\title{
Analysis of EGFR signaling pathway in nasopharyngeal carcinoma cells by quantitative phosphoproteomics
}

\author{
Lin Ruan ${ }^{1,2 \dagger}$, Xin-Hui Li ${ }^{1 \dagger}$, Xun-Xun Wan ${ }^{1,3+}$, Hong Yi ${ }^{1}$, Cui Li ${ }^{1}$, Mao-Yu Li ${ }^{1}$, Peng-Fei Zhang ${ }^{1}$, Gu-Qing Zeng ${ }^{1}$, \\ Jia-Quan Qu', Qiu-Yan He' ${ }^{1}$ Jian-Huang Li ${ }^{1}$, Yu Chen ${ }^{1}$, Zhu-Chu Chen ${ }^{1}$ and Zhi-Qiang Xiao ${ }^{1 *}$
}

\begin{abstract}
Background: The epidermal growth factor receptor (EGFR) is usually overexpressed in nasopharyngeal carcinoma (NPC) and is associated with pathogenesis of NPC. However, the downstream signaling proteins of EGFR in NPC have not yet been completely understood at the system level. The aim of this study was identify novel downstream proteins of EGFR signaling pathway in NPC cells.
\end{abstract}

Results: We analyzed EGFR-regulated phosphoproteome in NPC CNE2 cells using 2D-DIGE and mass spectrometry analysis after phosphoprotein enrichment. As a result, 33 nonredundant phosphoproteins including five known EGFR-regulated proteins and twenty-eight novel EGFR-regulated proteins in CNE2 were identified, three differential phosphoproteins were selectively validated, and two differential phosphoproteins (GSTP1 and GRB2) were showed interacted with phospho-EGFR. Bioinformatics analysis showed that 32 of 33 identified proteins contain phosphorylation modification sites, and 17 identified proteins are signaling proteins. GSTP1, one of the EGFRregulated proteins, associated with chemoresistance was analyzed. The results showed that GSTP1 could contribute to paclitaxel resistance in EGF-stimulated CNE2 cells. Furthermore, an EGFR signaling network based on the identified EGFR-regulated phosphoproteins were constructed using Pathway Studio 5.0 software, which includes canonical and novel EGFR-regulated proteins and implicates the possible biological roles for those proteins.

Conclusion: The data not only can extend our knowledge of canonical EGFR signaling, but also will be useful to understand the molecular mechanisms of EGFR in NPC pathogenesis and search therapeutic targets for NPC.

\section{Background}

Nasopharyngeal carcinoma (NPC) is one of the most common malignant tumors in Southern China [1]. Although NPC is a relatively radiosensitive disease, some of the NPC patients present local recurrences and distant metastases after radiotherapy due to radioresistance and the majority of these patients surrender recurrence and metastasis within 1.5 year after treatment [2]. Hence, development of a specific targeted therapy for NPC is urgent for improving the patient survival and prognosis. Uncovering signaling pathway involved in

\footnotetext{
* Correspondence: zqxiao2001@hotmail.com

† Contributed equally

'Key Laboratory of Cancer Proteomics of Chinese Ministry of Health, Xiangya Hospital, Central South University, Changsha 410008, China
}

Full list of author information is available at the end of the article
NPC cancer biology will provide important information on targeted therapy for this disease.

Overexpression of epidermal growth factor receptor (EGFR) is common in NPC [3-5], and most NPC cell lines and about $85 \%$ of the Chinese patients with NPC have moderate to strong expression of EGFR [6,7]. Moreover, overexpression of EGFR in primary tumors was associated with tumor metastasis, recurrence, and poor survival in patients with NPC $[7,8]$. Recent data have proposed EGFR as a new target for NPC therapy $[9,10]$. These studies suggest that EGFR plays a crucial role in the development and progression of NPC. EGFR is one of the most studied receptor tyrosine kinases. The natural ligands EGF and TGF- $\alpha$ bind to the extracellular domain of EGFR, and activate the receptor and its downstream signal proteins, ultimately causing activation or modulation of various cellular

\section{() Biomed Central}

(c) 2011 Ruan et al; licensee BioMed Central Ltd. This is an Open Access article distributed under the terms of the Creative Commons Attribution License (http://creativecommons.org/licenses/by/2.0), which permits unrestricted use, distribution, and reproduction in any medium, provided the original work is properly cited. 
processes [11]. About 200 targets of EGFR signaling pathway have been reported [12], and 177 molecules involved in EGFR signaling pathway are listed in the Human Protein Reference Database http://www.hprd. org, but the downstream signaling proteins of EGFR in NPC have not yet been completely understood at the system level.

Signaling transduction is regulated by the phosphorylation and dephosphorylation of proteins. Phosphoproteomics has an advantage for investigating cellular signaling pathways by simultaneously identifying a number of phosphoproteins at one experiment, but it also has a technical challenge because of the low abundance of phosphoproteins in cells. Therefore, enrichment of phosphoproteins is necessary before starting a phophoproteomic analysis to increase the sensitivity of identifying phosphoproteins. Two-dimensional difference gel electrophoresis (2D-DIGE) is a quantitative proteomics approach with great sensitivity and accuracy of quantitation compared to a conventional 2-DE. Using the 2DDIGE, different samples prelabeled with mass- and charge-matched fluorescent cyanine dyes are co-separated in the same $2 \mathrm{D}$ gel, and an internal standard is used in every gel, overcoming the problem of intergel variation in classical 2-DE. Therefore, $2 \mathrm{D}$-DIGE is able to efficiently provide accurate and reproducible differential expression values for proteins in two or more biological samples $[13,14]$.

To identify EGFR signaling proteins in NPC cells, in this study quantitative phosphoproteomics based on phosphate metal affinity chromatography-enriched phosphorproteins, 2D-DIGE and mass spectrometry analysis was applied to identify phosphoproteins after EGFR activation in NPC cells. We identified 33 EGFR-regulated phosphoproteins, and constructed an EGFR signaling network based on the identified phosphoproteins in NPC cells. The functional validation showed that GSTP1, one of the EGFR-regulated proteins, is involved in paclitaxel resistance in EGF-stimulated CNE2 cells. The data will provide insights into our understanding of EGFR signaling pathway and may have implications on target-directed therapeutics for NPC.

\section{Methods}

\section{Cell culture and EGF treatment}

NPC cell line CNE2 cells were cultured to $60-70 \%$ confluency in DMEM medium supplemented with $10 \%$ fetal bovine serum (Invitrogen) at $37^{\circ} \mathrm{C}$, serum-starved for 24 $\mathrm{h}$, and then were stimulated with $30 \mathrm{ng} / \mathrm{mL}$ EGF (Sigma) or mock-treated as a control. In EGFR blocking experiments, cells were pretreated with $1 \mu \mathrm{m}$ EGFR tyrosine kinase inhibitor PD153035 (Calbiochem), and followed by incubation with EGF.

\section{Phosphoprotein enrichment}

A phosphoprotein purification kit (BD Biosciences) was applied to enrich phosphoproteins from EGF-stimulated or unstimulated CNE2 cells according to the manufacturer's instructions. To validate the efficacy of phosphoprotein enrichment, $40 \mu \mathrm{g}$ of proteins from total cellular lysate, elution fraction containing the highly-concentrated and purified phosphoproteins, and flow-through fraction were separated by $6 \%$ SDS-PAGE, followed by Western blotting using anti-phosphotyrosine antibody (4G10, Upstate). The concentration of the phosphoproteins was determined using a 2-D Quantification Kit (Amersham Biosciences).

\section{Protein labeling}

Phosphoproteins from the elution fractions were precipitated using chloroform-methanol as described by Wessel and Flugge [15], resolubilized in 2D-DIGE sample buffer (30 mM Tris, $7 \mathrm{M}$ urea, $2 \mathrm{M}$ thiourea, 4\% CHAPS, pH 8.5), and adjusted to $\mathrm{pH}$ 8.5. Equal amount phosphoproteins from six samples (three biological repeats) were pooled together as the internal standard. Three EGF-stimulated samples and three EGF-unstimulated samples were randomly labeled with $\mathrm{Cy} 3$ or $\mathrm{Cy} 5$, while internal standards were labeled with Cy2, using 200 pmol fluorochrome/25 $\mu \mathrm{g}$ protein (Amersham Biosciences). Labeling reactions were performed on ice in the dark for $30 \mathrm{~min}$, and then quenched by the addition of $1 \mu \mathrm{L} 10 \mathrm{mM}$ lysine (Sigma) for $10 \mathrm{~min}$.

\section{D-DIGE}

Cy3- and Cy5-labelled samples $(25 \mu \mathrm{g})$ from each pair of EGF-treated and untreated cells were combined before mixing with $25 \mu \mathrm{g}$ Cy2-labelled internal standards. An equal volume of $2 \times$ sample buffer ( $8 \mathrm{M}$ urea, $130 \mathrm{mM}$ DTT) was added to the sample and the total volume was made up to $450 \mu \mathrm{L}$ with rehydration buffer (8 M urea, 4\% CHAPS, 1\% Biolyte, pH 4-7, 13 mM DTT). The samples were applied to IPG strips [pH 4-7; nonlinear (NL), $24 \mathrm{~cm}$ ] and focused on an IPGphor (Amersham Biosciences). The focused IPG strips were equilibrated, and then were transferred to the tops of $12.5 \%$ polyacrylamide gels and run for about $7 \mathrm{~h}$, using low-fluorescence glass plates on an Ettan DALT II system (Amersham Biosciences). All electrophoresis procedures were performed in the dark. The biological triplicate EGF-stimulated and unstimulated cells and the internal standard were run on three gels as analytic gels. In addition, we performed another strip in parallel as a preparative gel for spot pickings, as described above, except that the IPG strip was loaded with $1000 \mu \mathrm{g}$ proteins and the gel was stained with Coomassie brilliant blue. After SDS-PAGE, the three analytic gels were scanned on a Typhoon 9410 scanner (GE Healthcare) at 
appropriate excitation/emission wavelengths specific for Cy2 (488/520 nm), Cy3 (532/580 nm) and Cy5 (633/670 $\mathrm{nm})$, to generate nine protein spot maps.

\section{Image analysis}

Images were cropped using ImageQuant TL 2005 software (GE Healthcare) from 2D-DIGE gels, and analyzed using DeCyder 6.5 software (GE Healthcare) according to the manufacturer's recommendations. The DeCyder differential in-gel analysis (DIA) module was used for pairwise comparisons of each EGF-stimulated and unstimulated cell sample to the internal standard in each gel. The DeCyder biological variation analysis (BVA) module was then used to simultaneously match all nine proteinspot maps and, using the Cy3: $\mathrm{Cy} 2$ and $\mathrm{Cy} 5$ : $\mathrm{Cy} 2$ DIA ratios, to calculate average abundance changes and paired Student's $t$-test $p$ values for the variance of these ratios for each protein pair across all samples. The differential protein spots (ratio $\geq 1.5, p \leq 0.05$ ) that altered consistently in all nine protein-spot maps were selected for identification.

\section{Protein identification by MS}

All the differential phosphoprotein spots were excised from stained preparative gels using punch, destained, and in-gel trypsin digestion was performed as previously described by us [16]. Briefly, the gel spots were destained with $100 \mathrm{mM} \mathrm{NH} 4 \mathrm{HCO} 3$ in 50\% acetonitrile, dried in a vacuum centrifuge, and incubated in the digestion solution $(40 \mathrm{mM}$ NH4HCO3, $9 \%$ acetonitrile, and $20 \mu \mathrm{g} / \mathrm{mL}$ proteomics grade trypsin) at $37^{\circ} \mathrm{C}$ for $14-16 \mathrm{~h}$. The resulted peptides were extracted with $50 \%$ acetonitrile/ 2.5\% TFA, purified with ZipTip C18 column (Millipore) and mixed with CCA matrix solution[4-hydroxy- $\alpha$ cyanocinnamic acid (HCCA; Sigma) in 30\% ACN/0.1\% TFA] followed by analysis with Voyager System DE-STR 4307 MALDI-TOF Mass Spectrometer (ABI) to obtain the peptide mass fingerprint (PMF). The standard peptide mixture was analyzed at the same time to correct the machine. The parameters of MALDI-TOF were set up as follows: positive ionreflector mode, accelerating voltage $20 \mathrm{kV}$, grid voltage $64.5 \%$, mirror voltage ratio 1.12 , N2 laser wavelength $337 \mathrm{~nm}$, pulse width $3 \mathrm{~ns}$, the number of laser shots 50 , acquisition mass range 500-3000 Da, delay $100 \mathrm{~ns}$, and vacuum degree $4 \times 10^{-7}$ Torr.

In peptide mass fingerprint map database searching, Mascot Distiller was used to obtain the monoisotopic peak list from the raw mass spectrometry files. Peptide matching and protein searches against the Swiss-Prot database were performed using the Mascot search engine http://www.matrixscience.com/ with a mass tolerance of \pm 50 p.p.m. Protein scores of $\geq 56$ (threshold) indicate identity or extensive homology $(P<0.05)$ and were considered significant.

\section{Bioinformatics analysis}

To do phosphorylation site prediction of the identified proteins, we used on-line PhosphoSitePlus ${ }^{\mathrm{TM}}$ system biology resource http://www.phosphosite.org/ and the Phospho.ELM database http://phospho.elm.eu.org/index. html for predicting the presence of the phosphorylation modification sites [17], and PubMed database searching http://www.ncbi.nlm.nih.gov for comparing with the phosphorylated proteins reported in the literature. In addition, KEGG pathway analysis of the identified proteins was done in DAVID bioinformatics resources $[18,19]$.

\section{Validation of EGFR signaling phosphoproteins by IP-Western blotting}

Cells were lysed in the lysis buffer containing $150 \mathrm{mM}$ $\mathrm{NaCl}, 50 \mathrm{mM}$ Tris-HCl (pH 7.4), 1 mM EDTA, 1\% Ttiton $\mathrm{X}-100,1 \% \mathrm{NP}-40$ supplemented with phosphatase inhibitor cocktail 1 and 2 (Sigma-Aldrich) at $4^{\circ} \mathrm{C}$, and subsequently centrifuged at $12000 \mathrm{~g}$ for $30 \mathrm{~min}$ at $4^{\circ} \mathrm{C}$. Total cellular proteins were immunoprecipitated with protein G Sepharose (Amersham Biosciences), and antitarget protein antibody overnight at $4^{\circ} \mathrm{C}$. Immunocomplexes were used for Western blotting. Briefly, proteins were separated by $7 \%$ SDS-PAGE, and transferred to a PVDF membrane. Blots were blocked with 3\% BSA for $1 \mathrm{~h}$ at room temperature, and then incubated with primary antibody, followed by incubation with HRP-conjugated secondary antibodies for $1 \mathrm{~h}$ at room temperature. The signal was visualized using ECL detection reagent.

\section{Transient transfection}

The cells were transfected with GSTP1 siRNA or control siRNA (Santa Cruz Biotechnology) according to the siRNA transfection protocol provided by the manufacturer. Briefly, the day before transfection, CNE2 cells were plated into 6-well plates at the density of $10^{5}$ cells/ $\mathrm{mL}$ in DMEM medium containing 10\% FBS (Invitrogen). When the cells were $60-80 \%$ confluent, they were transfected with $10 \mathrm{nmol} / \mathrm{L}$ of GSTP1 siRNA or control siRNA in serum-free DMEM medium using Lipofectamine 2000 reagent (Invitrogen). $4 \mathrm{~h}$ after the beginning of the transfection, the medium was replaced with DMEM medium containing 10\% FCS, and continued to culture the cells for additional $44 \mathrm{~h}$, and then GSTP1 expression level was determined by Western blotting.

\section{Flow cytometry analysis of apoptotic cells after treatment of paclitaxel and EGF}

At the end of the transfection, the cells were incubated with $30 \mathrm{nM}$ paclitaxel and $30 \mathrm{ng} / \mathrm{mL}$ EGF for $48 \mathrm{~h}$, and cell apoptosis was examined by flow cytometry as previously described by us [20]. Briefly, cells were harvested, fixed with ice-cold $70 \%$ ethanol in PBS at $-20^{\circ} \mathrm{C}$ for $1 \mathrm{~h}$ and then centrifuged at $1500 \mathrm{rpm}$ for $5 \mathrm{~min}$. The 
pellets were incubated with $0.5 \%$ Triton X-100 (Sigma) and $0.05 \%$ RNase (Sigma) in $1 \mathrm{~mL}$ PBS at $37^{\circ} \mathrm{C}$ for 30 $\mathrm{min}$, and then centrifuged at $1500 \mathrm{rpm}$ for $5 \mathrm{~min}$. The cell pellets were incubated with $40 \mu \mathrm{g} / \mathrm{mL}$ propidium iodide (Sigma) in $1 \mathrm{~mL}$ PBS at room temperature for 30 min. Samples were immediately analyzed by a FACScan flow cytometry (Becton Dickinson). Apoptosis was evaluated based on the proportion of sub-G1 hypodiploid cells. Three independent experiments were done.

\section{Analysis of cell viability by MTT after treatment of paclitaxel and EGF}

At the end of the transfection, the cells were incubated with the different concentrations of paclitaxel and 30 $\mathrm{ng} / \mathrm{mL}$ EGF for $48 \mathrm{~h}$, and cell viability was examined using MTT assay as previously described by us [20]. Briefly, $20 \mu \mathrm{l}$ of $5 \mathrm{mg} / \mathrm{mL}$ MTT (Sigma) was added to each well, and the medium was removed after $4 \mathrm{~h}$ of incubation. $150 \mu \mathrm{L}$ DMSO (Sigma) was added to each well for $10 \mathrm{~min}$ at room temperature. The absorbance of each well was read with a Bio-Tek Instruments EL310 Microplate Autoreader at $490 \mathrm{~nm}$. Three independent experiments were done.

\section{Network modeling}

To construct EGFR signaling network (biological interaction network of the proteins) of identified phosphoproteins, functional and pathway analyses were performed using Pathway Studio 5.0 software, a tool for the description of networks and signaling pathways [21].

\section{Results \\ Enrichment of phosphoproteins in EGF-stimulated and unstimulated NPC cells}

A commercial phosphoprotein enrichment kit based on phosphate metal affinity chromatography was used to enrich phosphoproteins from EGF-stimulated and unstimulated NPC CNE2 cells. Typically, the elution fraction contains highly-concentrated and purified phosphoproteins. As shown in Figure 1A, levels of phosphorylated EGFR in CNE2 reached the high peak 15 min after 30 ng/mL EGF-stimulated cells. Then the total proteins of cells treated by $\mathrm{ng} / \mathrm{mL}$ EGF for $15 \mathrm{~min}$ were used to enrich phosphoproteins. As shown in Figure 1B, the elution fractions contained more phosphoproteins compared with the total cellular proteins and flow-through fractions, indicating that the elution fractions can be used to identify EGFR-regulated phosphoproteins.

\section{Identification of differential phosphoproteins in EGF-stimulated and unstimulated NPC cells by 2D-DIGE and MS}

2D-DIGE and MS analysis were performed to identify differential phosphoproteins in EGF-stimulated and unstimulated (control) CNE2 cells. As shown in Figure 2A, phosphoproteins were labeled with either $\mathrm{Cy} 3$ (EGF-stimulated cells) or Cy5 (control) fluorescent dyes, while internal standards were labeled with Cy2. The interchangeable use of either $\mathrm{Cy} 3$ or $\mathrm{Cy} 5$ for each experiment has already been established. After 2DDIGE, the Cy2, Cy3 and Cy5 images were scanned and analyzed using DeCyder software. 38 protein spots were differentially expressed in all nine protein-spot maps (Figure 2B left); 33 nonredundant proteins were identified by MS (Table 1); among them, five proteins are known EGFR-regulated proteins (KRT8, hnRNPK, KRT18, GRB2, Stathmin), and the other twenty-eight proteins have not been reported as EGFR-regulated proteins. A close-up of the region of 2D-DIGE gel images and a three-dimensional (3D) simulation of spots 22 and 33 significantly up-regulated in EGF-stimulated cells compared with control are shown in Figure 2B (right). MALDI-TOF-MS analysis and database matching identified spot 22 as Glutathione S-transferase P 1 (GSTP1) with high sequence coverage and mass accuracy (Figure 2C).

\section{Bioinformatics analysis of the identified proteins}

Phosphorylation modification sites of 33 identified proteins were analyzed with two online resources (PhosphoSitePlusTM system biology resource, and the Phospho. ELM database) to confirm the identified proteins being phosphoproteins. The results showed that 32 of 33 identified proteins contain phosphorylation modification sites except BAG5 (Table 1). In addition, KEGG pathway analysis showed that 17 identified proteins (HSP7C, KRT8, TUBB, VIM, HSP60, PCNA, RSSA, CKB, ATP5H, STMN1, GSTP1, KRT18, NME1, HSP27, GRB2, PARK7, and $3 \mathrm{HIDH}$ ) are signaling proteins involved in MAPK, JAK/STAT and VEGF pathways, etc.. Taken together, these results support that the proteins identified by phophoproteomics are phosphoproteins.

\section{Validation of identified phosphoproteins}

To confirm the results of phosphoproteomics, we detected the phosphorylated levels of three identified proteins (ANXA3, KRT8, and KRT18) by IP-Western blotting. Following immunoprecipitation (IP) of ANXA3, KRT8, and KRT18 from total cellular proteins, immunocomplexes were analyzed by Western blotting using antiphosphotyrosine antibody. As shown in Figure 3A, the levels of phosphotyrosine of ANXA3, KRT8, and KRT18 were significantly higher in the $30 \mathrm{ng} / \mathrm{mL}$ EGF-stimulated CNE2 cells than in EGF-unstimulated CNE2 cells, and tyrosine phosphorylation of ANXA3, KRT8, and KRT18 could be blocked by the pretreatment of the cells with 1 $\mu \mathrm{m}$ EGFR inhibitor PD153035. The results indicate that EGFR activation can induce phosphorylation of ANXA3, 


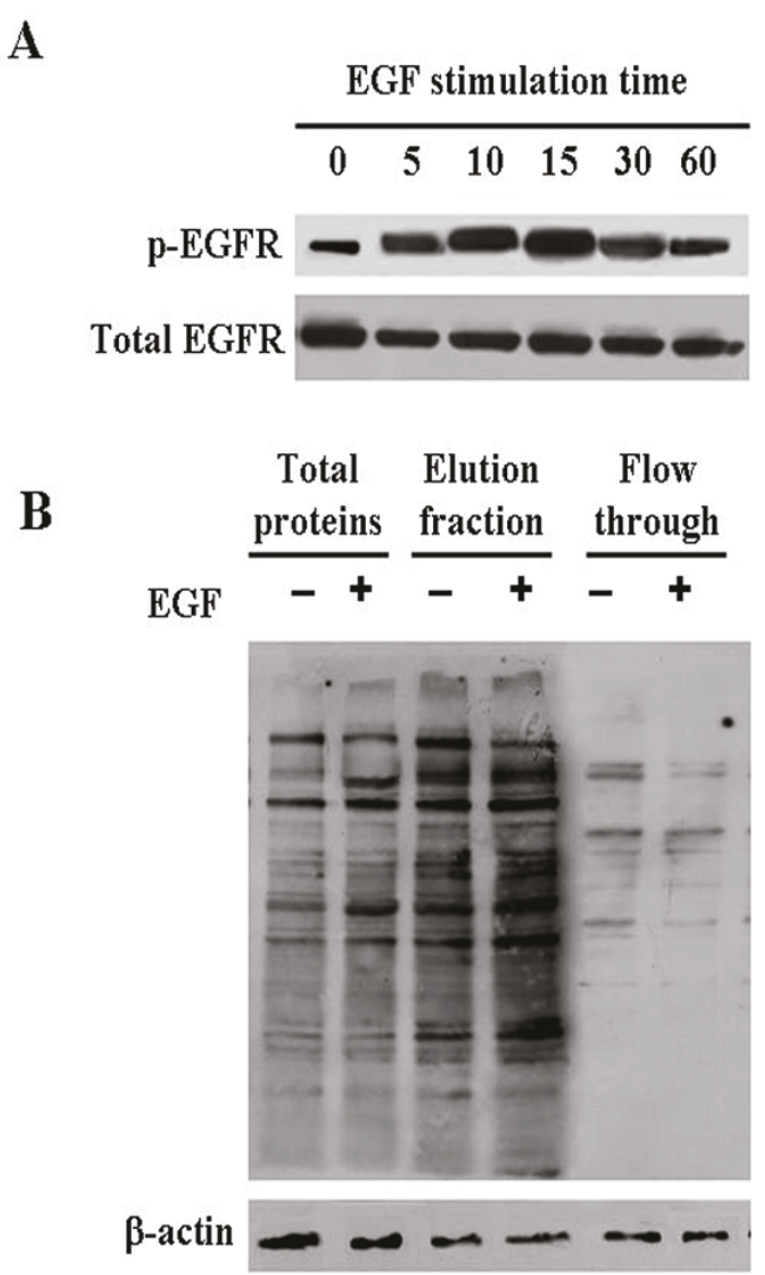

Figure 1 Enrichment of phosphoproteins in EGF-stimulated and unstimulated NPC cells. A, Detection of EGFR activation by Western blotting. CNE-2 cells were stimulated with $30 \mathrm{ng} / \mathrm{mL}$ EGF for different times, and Western blotting was performed to detect levels of phosphorylated EGFR in total cellular proteins. Total EGFR serves as a loading control. B, Enrichment of phosphoproteins. Phosphoprotein enrichment kit was used to enrich phosphoproteins from total cellular proteins of EGF-stimulated and unstimulated CNE2 cells, and Western blotting analysis of phosphoproteins using anti-phosphotyrosine antibody $(4 \mathrm{G} 10)$ in the total cellular protein, elution fraction and flow through fraction. $\beta$-actin serves as a loading control.

KRT8, and KRT18, which is consistent with results of phosphoproteomics.

\section{Interaction of identified proteins with phospho-EGFR}

IP-Western blotting were performed detect whether activated (phosphorylated) EGFR interacted with the two identified phosphoproteins (GSTP1 and GRB2) in CNE2 cells. As shown in Figure 3B, GSTP1 and GRB2 could be detected in the immunoprecipitation complex of phospho-EGFR antibody in $30 \mathrm{ng} / \mathrm{mL}$ EGF-stimulated CNE2 cells, and could not be detected by the pretreatment of the cells with $1 \mu \mathrm{m}$ EGFR inhibitor PD153035, which indicates that GSTP1 and GRB2 can interact with phospho-EGFR, are downstream targets of EGFR signaling pathway.

\section{Association of EGFR-regulated GSTP1 with chemoresistance}

To study the functional role of EGFR-regulated GSTP1 in CNE2 cells, CNE2 cells were transfected with GSTP1 siRNA. As shown in Figure 4A, GSTP1 siRNA transfection knocked down GSTP1 expression in CNE2 cells, whereas GSTP1 expression was not significantly suppressed by control siRNA. We next evaluated the effects of GSTP1 siRNA transfection on the paclitaxel sensitivity in EGF-stimulated CNE2 cells. CNE2 cells transfected with GSTP1 siRNA or control siRNA were incubated with paclitaxel and EGF for additional $48 \mathrm{~h}$. And then the cell apoptosis and cell viability were examined using flow cytometry and MTT assay, respectively. As Figure $4 \mathrm{~B}$ and $4 \mathrm{C}$ shown, compared with control 


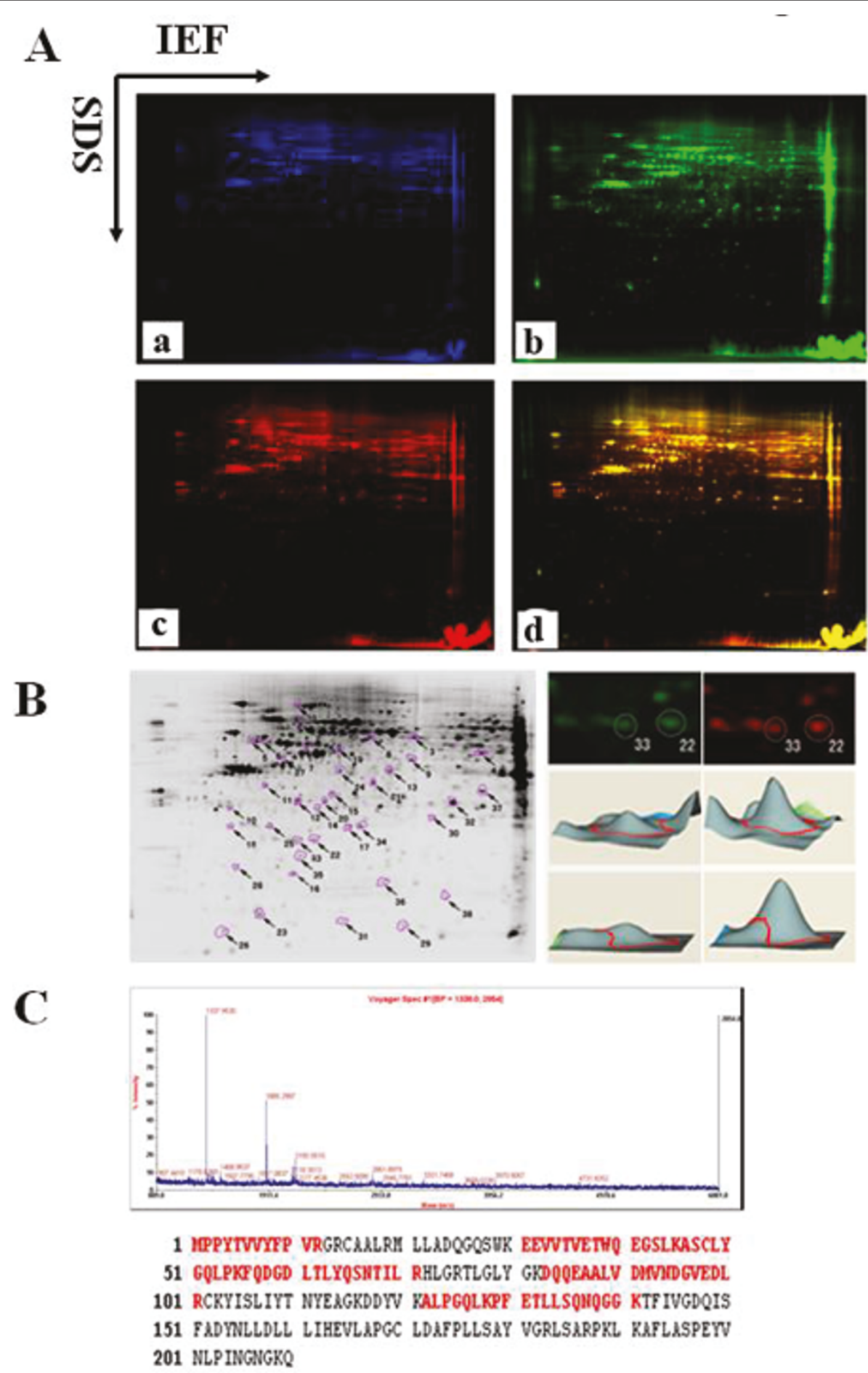

Figure 2 Comparative phosphoproteomics analysis of EGF-stimulated and unstimulated NPC cells by 2D-DIGE and MS. A, Representative 2D-DIGE gel images. Internal standard labeled with Cy2 (a, blue), phosphoproteins from EGF-unstimulated cells labeled with Cy3 (b, green), phosphoproteins from EGF-stimulated cells labeled with Cy5 (c, red), and overlaying Cy3 and Cy5 images (d, yellow). B, (Left) the 38 differential phosphoprotein spots detected by Decyder software; (Right) a close-up of the region of 2D-DIGE gel images and a 3D simulation of spots 22 and 33. C, MALDI-TOF-MS analysis of differential protein spot 22. Mass spectrum of spot 22 identified as GSTP1 according to the matched peaks is shown (top). Protein sequence of GSTP1 is shown, and matched peptides are labeled in red letters (bottom). 
Table 1 Identification of differential phosphoproteins in EGF-stimulated and unstimulated NPC CNE2 cells by 2-D DIGE and MS

\begin{tabular}{|c|c|c|c|c|c|c|c|c|c|c|c|}
\hline \multirow[t]{2}{*}{ No. } & \multirow[t]{2}{*}{ Protein name } & \multirow[t]{2}{*}{$\begin{array}{l}\text { Gene } \\
\text { name }\end{array}$} & \multirow[t]{2}{*}{$\begin{array}{l}\text { Uniprot } \\
\text { accession }\end{array}$} & \multirow[t]{2}{*}{$\begin{array}{l}M w \\
(\mathrm{Da})\end{array}$} & \multirow[t]{2}{*}{$p l$} & \multirow{2}{*}{$\begin{array}{l}\text { Number } \\
\text { of } \\
\text { Matched } \\
\text { peptides }\end{array}$} & \multirow{2}{*}{$\begin{array}{c}\text { Sequence } \\
\text { coverage } \\
\text { (\%) }\end{array}$} & \multirow[t]{2}{*}{ Score } & \multicolumn{2}{|c|}{$\begin{array}{c}\text { Ratio } \\
\text { (experiment/ } \\
\text { control) }\end{array}$} & \multirow[t]{2}{*}{$\begin{array}{l}\text { Phosphorylation } \\
\text { sites }\end{array}$} \\
\hline & & & & & & & & & Ratio & $t$ test & \\
\hline 1 & $\begin{array}{c}\text { Translation endoplasmic reticulam } \\
\text { ATPase (TERA) }\end{array}$ & VCP & P55072 & 89950 & 5.14 & 16 & $31 \%$ & 148 & 1.75 & 0.0082 & Yes \\
\hline 2 & Heat shock cognate $71 \mathrm{kDa}$ protein & HSP7C & P11142 & 71082 & 5.37 & 13 & $38 \%$ & 118 & -1.51 & 0.018 & Yes \\
\hline 3 & Keratin,type II cytoskeletal 8 & KRT8 & P05787 & 53671 & 5.52 & 18 & $43 \%$ & 139 & 3.47 & 0.0035 & Yes \\
\hline 4 & $\begin{array}{l}\text { BAG family molecular chaperone } \\
\text { regulator } 5\end{array}$ & BAG5 & Q9UL15 & 51738 & 5.76 & 4 & $15 \%$ & 56 & -2.51 & 0.0001 & No \\
\hline 5 & TUBB protein & TUBB & P07437 & 50095 & 4.78 & 25 & $62 \%$ & 278 & 3.12 & 0.0009 & Yes \\
\hline 6 & Vimentin & VIM & P08670 & 53676 & 5.06 & 12 & $30 \%$ & 102 & 1.99 & 0.0056 & Yes \\
\hline 7 & $\begin{array}{l}\text { Heterogeneous nuclear } \\
\text { ribonucleoprotein } \mathrm{K}\end{array}$ & hnRNPK & P61978 & 51230 & 5.39 & 8 & $31 \%$ & 86 & 2.89 & 0.0005 & Yes \\
\hline 8 & 60KD Heat shock protein & HSP60 & P10809 & 61187 & 5.70 & 12 & $29 \%$ & 109 & 2.20 & 0.008 & Yes \\
\hline 9 & Keratin,type II cytoskeletal 8 & KRT8 & P05787 & 53671 & 5.52 & 6 & $36 \%$ & 85 & 1.63 & 0.032 & Yes \\
\hline 10 & Proliferating cell nuclear antigen & PCNA & P12004 & 29092 & 4.57 & 9 & $52 \%$ & 93 & 2.88 & 0.0001 & Yes \\
\hline 11 & $\begin{array}{c}\text { F-actin-capping protein subunit } \\
\text { beta }\end{array}$ & CAPZB & P47756 & 31616 & 5.36 & 5 & $26 \%$ & 56 & 2.23 & 0.009 & Yes \\
\hline 12 & laminin receptor 1 & RSSA & P08865 & 32947 & 4.79 & 7 & $38 \%$ & 76 & 1.76 & 0.0056 & Yes \\
\hline 13 & Creatine kinase B-type & CKB & P12277 & 42902 & 5.34 & 7 & $38 \%$ & 100 & 1.99 & 0.0021 & Yes \\
\hline 14 & Emerin & EMD & P50402 & 28994 & 5.29 & 6 & $21 \%$ & 77 & 1.71 & 0.0014 & Yes \\
\hline 15 & $\begin{array}{l}\text { Heterogeneous nuclear } \\
\text { ribonucleoproteins } \mathrm{C} 1 / \mathrm{C} 2\end{array}$ & $\begin{array}{l}\text { hnRNP } \\
\text { C1/C2 }\end{array}$ & P07910 & 33707 & 4.95 & 5 & $18 \%$ & 68 & 2.98 & 0.0008 & Yes \\
\hline 16 & $\begin{array}{l}\text { ATP synthase D chain } \\
\text { mitochondrial }\end{array}$ & ATP5H & O75947 & 18537 & 5.21 & 5 & $37 \%$ & 57 & 2.67 & 0.005 & Yes \\
\hline 17 & Prohibitin & $\mathrm{PHB}$ & P35232 & 29843 & 5.57 & 7 & $37 \%$ & 120 & -2.54 & 0.031 & Yes \\
\hline 18 & unidentified & & & & & & & & 1.79 & 0.002 & N/A \\
\hline 19 & Elongation factor 1- delta & EEF1D & P29692 & 32.217 & 4.9 & 4 & $25 \%$ & 72 & 1.81 & 0.026 & Yes \\
\hline 20 & Anamorsin & CIAPIN1 & Q6Fl81 & 34141 & 5.44 & 9 & $39 \%$ & 139 & 2.90 & 0.0001 & Yes \\
\hline 21 & Annexin A3 & ANXA3 & P12429 & 36524 & 5.63 & 7 & $27 \%$ & 83 & 2.83 & 0.0054 & Yes \\
\hline 22 & Glutathione S-transferase P1 & GSTP1 & P09211 & 23569 & 5.43 & 6 & $34 \%$ & 97 & 3.11 & 0.0013 & Yes \\
\hline 23 & unidentified & & & & & & & & 1.64 & 0.026 & N/A \\
\hline 24 & Keratin,typelcytoskeletal 18 & KRT18 & P05783 & 48029 & 5.34 & 13 & $36 \%$ & 141 & -2.86 & 0.029 & Yes \\
\hline 25 & $\begin{array}{c}\text { Ran-specific GTPase- activating } \\
\text { protein }\end{array}$ & RANBP1 & P43487 & 23310 & 5.71 & 6 & $32 \%$ & 98 & 1.89 & 0.034 & Yes \\
\hline 26 & unidentified & & & & & & & & 1.68 & 0.007 & N/A \\
\hline 27 & Tropomodulin-3 & TMOD3 & Q9NYL9 & 39.595 & 5.08 & 8 & $34 \%$ & 98 & 2.61 & 0.003 & Yes \\
\hline 28 & Myosin light polypeptide 6 & MYL6 & P60660 & 17090 & 4.56 & 6 & $50 \%$ & 70 & 2.80 & 0.0019 & Yes \\
\hline 29 & $\begin{array}{l}\text { Nucleoside diphosphate kinase A } \\
\text { (NDKA) }\end{array}$ & NME1 & P15531 & 17309 & 5.83 & 6 & $48 \%$ & 105 & -1.56 & 0.0023 & Yes \\
\hline 30 & Heat shock protein beta-1 & HSP27 & P04792 & 22826 & 5.98 & 7 & $47 \%$ & 84 & 2.65 & 0.0001 & Yes \\
\hline 31 & unidentified & & & & & & & & -2.72 & 0.038 & N/A \\
\hline 32 & $\begin{array}{c}\text { Growth factor receptor-bound } \\
\text { protein } 2\end{array}$ & GRB2 & P62993 & 25,206 & 5.89 & 7 & $39 \%$ & 75 & 2.60 & 0.00028 & Yes \\
\hline 33 & Glutathione S-transferase P1 & GSTP1 & P09211 & 23569 & 5.43 & 6 & $43 \%$ & 91 & 3.99 & $3.2 \mathrm{E}-06$ & Yes \\
\hline 34 & Peroxiredoxin-2 & PRDX2 & P32119 & 22049 & 5.66 & 6 & $54 \%$ & 98 & -1.69 & 0.042 & Yes \\
\hline 35 & c-Myc-responsive protein & $\mathrm{RCL}$ & O43598 & 19211 & 4.97 & 4 & $25 \%$ & 67 & 2.25 & 0.009 & Yes \\
\hline 36 & Protein DJ-1 & PARK7 & Q99497 & 19.891 & 6.33 & 5 & $30 \%$ & 65 & 2.99 & 0.0036 & Yes \\
\hline 37 & $\begin{array}{l}\text { 3-Hydroxyisobutyrate } \\
\text { dehydrogenase mitochondrial } \\
\text { precursor }(3 \mathrm{HIDH})\end{array}$ & $\mathrm{HIBADH}$ & P31937 & 35705 & 8.38 & 4 & $22 \%$ & 95 & -2.55 & 0.0051 & Yes \\
\hline 38 & Stathmin & STMN1 & P16949 & 17171 & 5.77 & 6 & $19 \%$ & 95 & 2.57 & 0.0023 & Yes \\
\hline
\end{tabular}




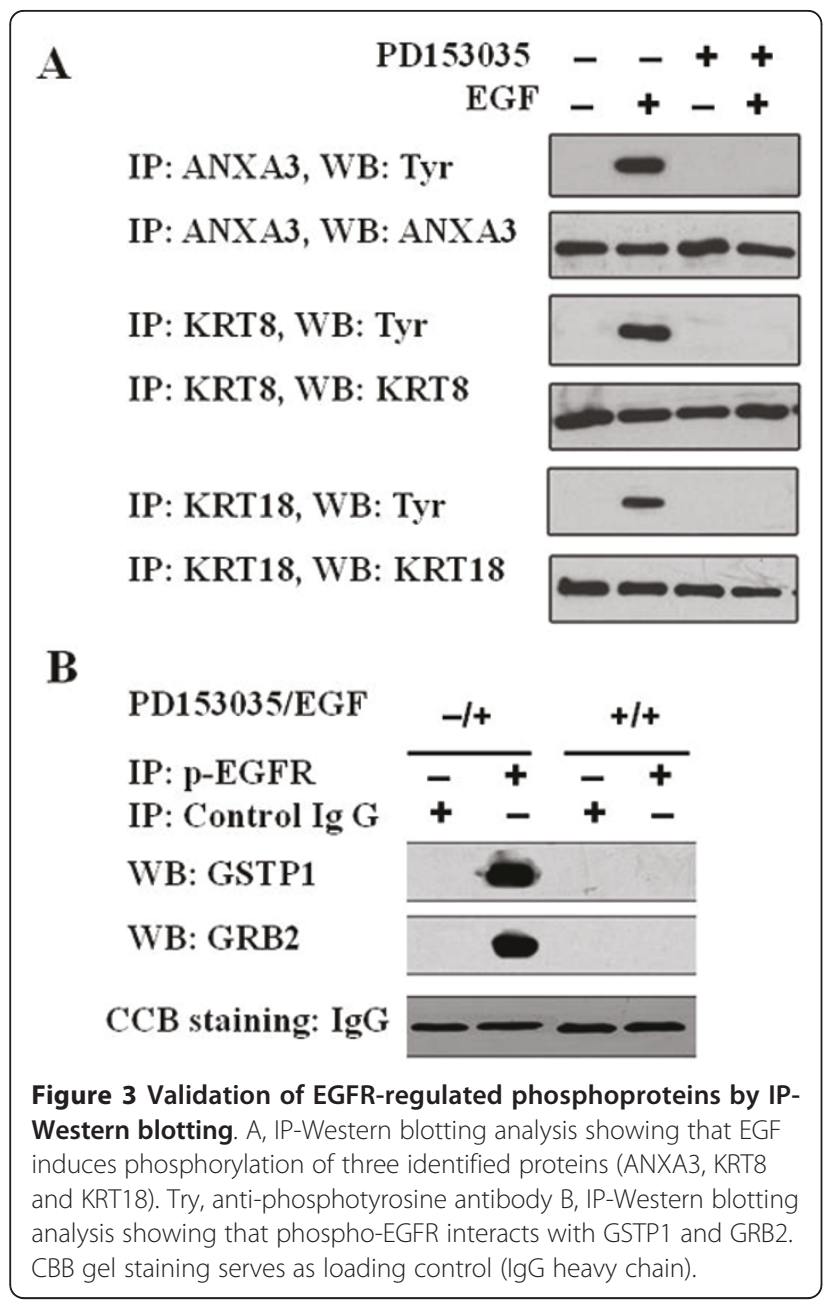

siRNA transfection, GSTP1 siRNA transfection could enhance EGF-stimulated CNE2 cells to paclitaxel sensitivity, with the significant increase of apoptotic cells and decrease of cell viability, which demonstrates that EGFR-regulated GSTP1 is involved in chemoresistance in CNE2 cells.

\section{Construction of EGFR signaling network in NPC cells}

Based on the identified phosphoproteins, we constructed EGFR signaling network using Pathway Studio 5.0 software. The result showed that $85 \%(28 / 33)$ proteins could be networked (Figure 5). The proteins that could be networked were linked by various relationships such as protein binding, protein interactions, modifications including phosphorylation, and expression regulation. The biological interaction network has a biological significance beyond static phosphoproteome data, suggesting that the majority of the proteins identified in this study were integral part of the dynamic complex of EGFR signaling.

\section{Discussion}

EGFR play an important role in development, progression and therapeutic resistance of NPC [6-8], but the role and mechanisms of EGFR in the NPC are not fully understood. Activation of EGFR initiates important cell signaling cascades such as PI3K/AKT/mTOR, JAK/ STAT, and Ras/Raf/MAPK pathways [22]. About 200 targets of EGFR signaling pathway have been reported [12], and 177 molecules involved in EGFR signaling pathway are listed in the Human Protein Reference Database http://www.hprd.org, but EGFR signaling pathway in NPC still needs to be elucidated.

In the present study, we used quantitative phosphoproteomics to identify EGFR-regulated phosphoproteins to elucidate EGFR signaling pathway in NPC cells at the system level. 33 proteins were identified in enriched phosphoproteins from EGFR-activated NPC CNE2 cells, and three phosphoproteins were validated by IP-Western blotting. Among the identified proteins, five are known EGFR signaling proteins and twenty-eight are novel EGFR signaling proteins. To confirm the phosphoproteins identified by phosphoproteomics, online bioinformatics resources were used to predict phosphorylation sites of 33 identified proteins. The results showed that 32 proteins contain phosphorylation modification sites. KEGG pathway analysis also showed that 17 identified proteins are signaling proteins. Taken together, these results support that the proteins identified by phosphoproteomics are phosphoproteins. Interestingly, our result showed that two identified proteins (GSTP1 and GRB2) could interact with phospho-EGFR in EGF-stimulated CNE2 cells, further supporting that the identified phosphoproteins are EGFR signaling proteins.

To uncover the biological context of EGFR signaling proteins, we constructed a biological interaction network of the identified phosphoproteins, which has biological significance beyond static phosphoproteome data. Interestingly, 28 of 33 identified phosphoproteins could be networked. This strongly suggests that the majority of the phophoproteins identified in this study were integral part of the dynamic complex of EGFR signaling. The proteins that could be networked were linked by various relationships such as protein binding, protein interactions, modifications including phosphorylation, and expression regulation. This biological interaction network will be useful for formulating testable hypotheses to understand the function of novel phosphorylated targets of EGFR signaling pathway in NPC cells.

GSTP1, a major drug-metabolizing and stress response signaling protein, belongs to GST family member [23]. Overexpression of GSTP1 has been reported in various types of human tumors, including colon cancer [24], gastric cancer [25], esophageal cancer [26], and head 


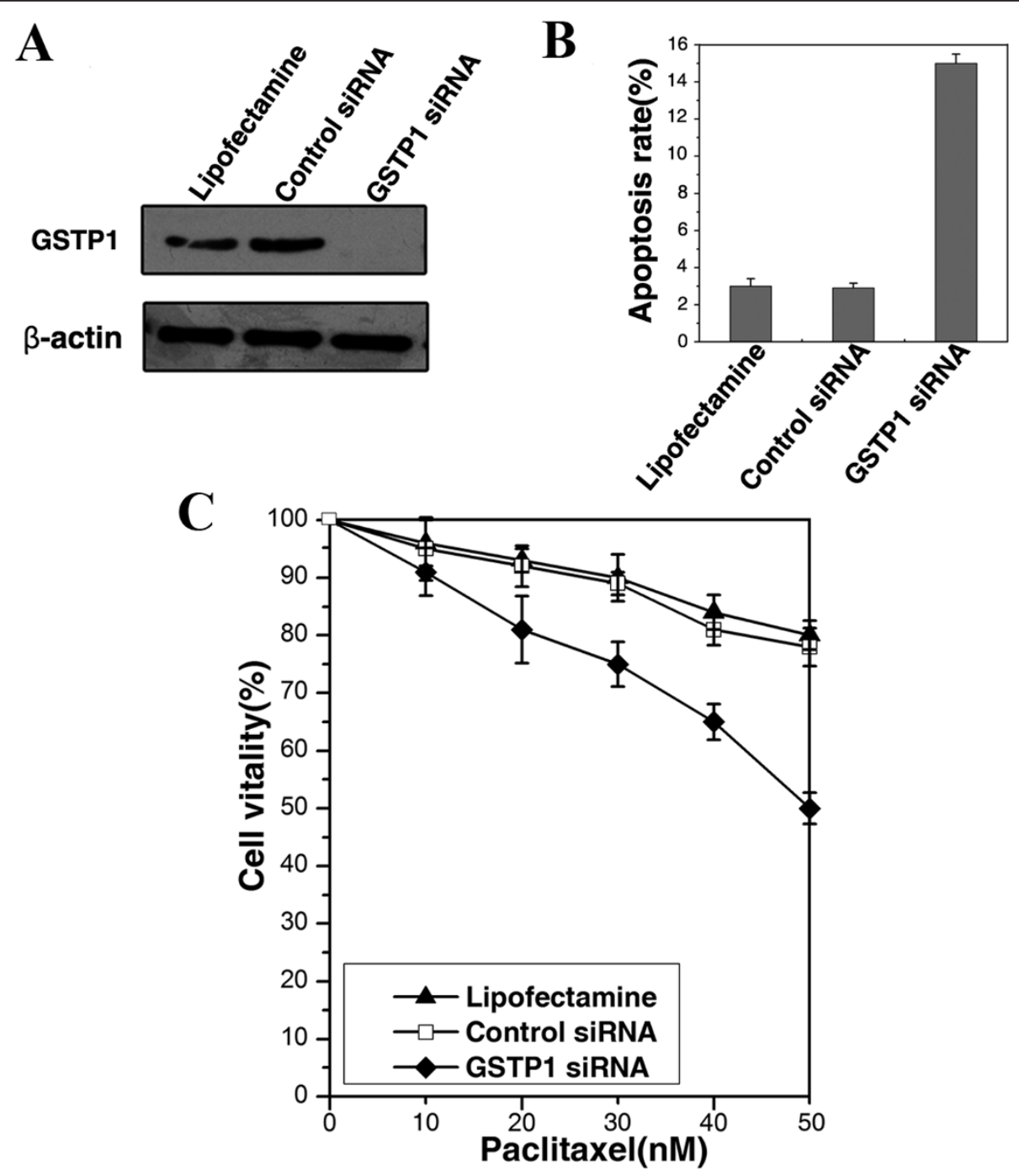

Figure 4 The effect of GSTP1 siRNA transfection on paclitaxel sensitivity in EGF-stimulated CNE2 cells. A, Western blotting analysis showed that transfection of CNE2 cells with GSTP1 siRNA knocked down GSTP1 expression, whereas GSTP1 expression was not significantly suppressed by control siRNA. B, Flow cytometric analysis showed that GSTP1 siRNA transfection could significantly increase cell apoptosis in CNE2 cells incubated with paclitaxel and EGF. C, MTT assay showed that GSTP1 siRNA transfection could significantly decrease the cell viability of CNE2 cells incubated with paclitaxel and EGF. Lipofectamine, cells treated with lipofectmine only.

and neck squamous carcinoma [27], and enhances human cancer cell chemoresistance [23,28]. Chen reported that $58 \%(83 / 143)$ primary NPC, $69.8 \%(30 / 43)$ recurrent NPC, and 65\% (13/20) metastatic NPC tissues highly expressed GSTP1 [29]. Jayasurya reported that all 55 NPC tissues showed positive GSTP1 immunoreactivity, and a significant correlation was found between GSTP1 expression and regional nodal metastasis of NPC [30]. In tumors with EGFR aberrant activation, GSTP1 was phosphorylated and activated, leading to drug inactivation and drug resistance [31]. Our results showed that activation of EGFR induced GSTP1 phosphorylation and interaction with EGFR, and GSTP1 is an important downstream target of EGFR signaling network in NPC cells. Overexpression of EGFR is frequent in NPC cell lines and tissues [6,7], and is associated with chemoresistance [32]. To explore the effect of EGFR-regulated GSTP1 in EGFR-induced chemoresistance in NPC cells, we evaluated the effects of GSTP1 knockdown on the paclitaxel sensitivity in EGF-stimulated CNE2 cells, and found that knockdown of GSTP1 expression by siRNA could increase EGF-stimulated CNE2 cells to paclitaxel sensitivity. It was obvious that GSTP1 is involved in EGFR-mediated chemoresistance in NPC cells. Our findings suggest that in NPC therapy, the double targeting of EGFR and GSTP1 could, potentially, be more effective than the current strategy of targeting either protein individually. 


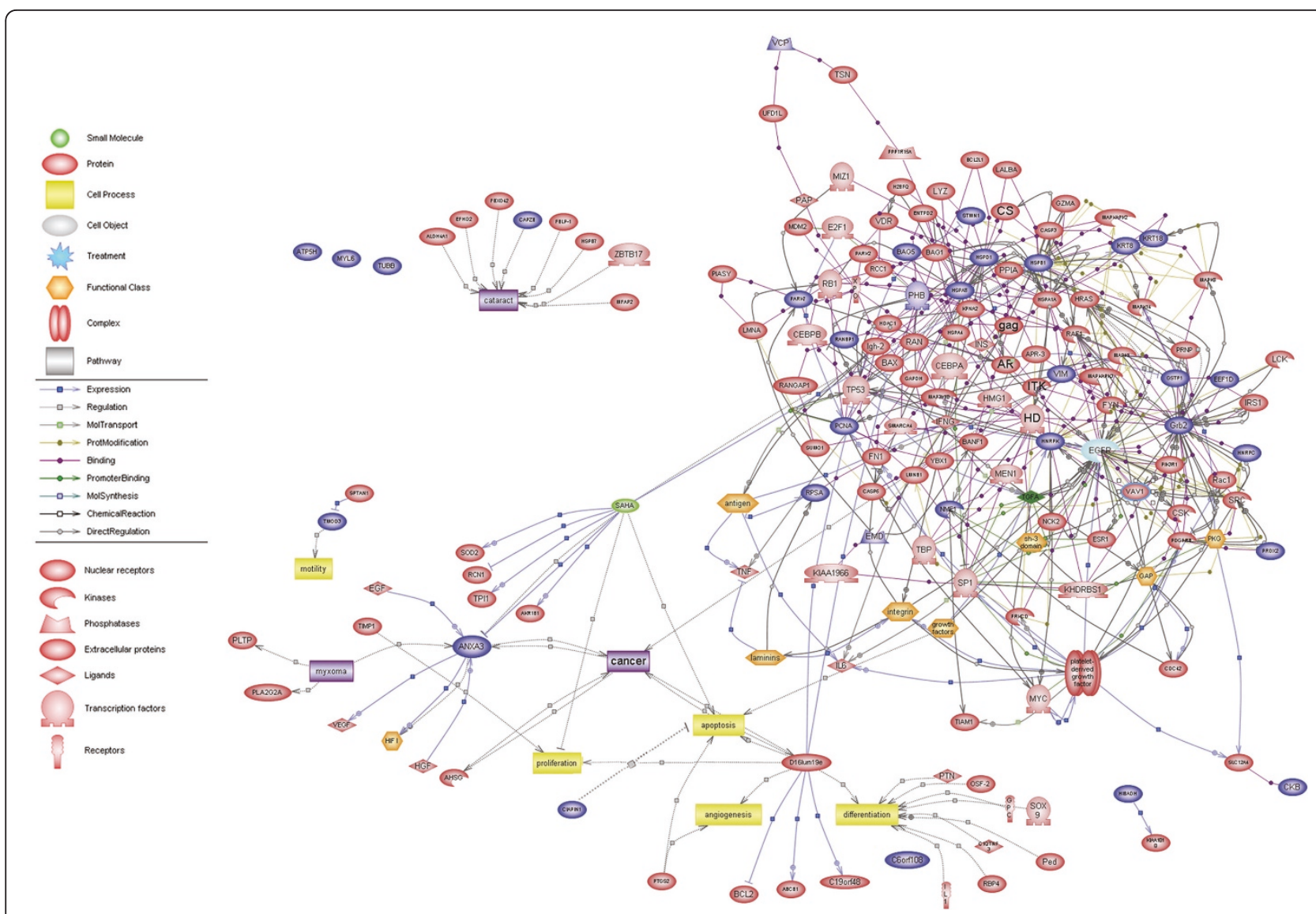

Figure 5 Signaling network of EGFR-regulated phosphoproteins in NPC cells. Proteins identified in Table 1 were imported into Pathway Studio, and an interaction map was generated with information from ResnetCore of Ariadne Genomics, and KEGG Pathway database. Legend of the interaction network is summarized on the right of the figure. Phosphoproteins, which are identified as phosphorylated targets of EGF signaling, were highlighted on the map (blue).

\section{Conclusion}

In this study, we identified 33 EGFR signaling proteins using quantitative phosphoproteomics, constructed an EGFR signaling network based the identified phosphoproteins in NPC cells, and validated that GSTP1, one of the EGFR-regulated proteins, is involved in chemoresistance in NPC cells. The data not only can extend our knowledge of canonical EGFR signaling, but also will be useful to understand the molecular mechanisms of EGFR in NPC pathogenesis and search therapeutic targets for NPC.

\section{Acknowledgements}

This work was supported by National Nature Science Foundation of China (30973290), Outstanding Scholars of New Era from Ministry of Education of China (2002-48), Lotus Scholars Program of Hunan Province, China (2007362), Key research program from Science and Technology Committee of Hunan Province, China (2010FJ2009), Aid program for Science and Technology Innovative Research Team in Higher Educational Institutions of Hunan Province, China, a project from Natural Science Foundation of Hunan Province, China(10JJ3045), and Scientific Research Fund from Higher Educational Institutions of Hunan Province, China(08C566).

\begin{abstract}
Author details
'Key Laboratory of Cancer Proteomics of Chinese Ministry of Health, Xiangya Hospital, Central South University, Changsha 410008, China. ${ }^{2}$ Key Laboratory of Allergy and Clinical Immunology, Department of Allergy, The Second Affiliated Hospital of Guangzhou Medical University, Guangzhou 510260, China. ${ }^{3}$ Department of Biochemistry and Molecular Biology, College of Medicine, Hunan Normal University, Changsha 410006, China.
\end{abstract}

\section{Authors' contributions}

ZQX designed the experiments and prepared the manuscript. LR, XHL and XXW performed most of the experiments. The other authors participated in the experiments. All authors read and approved the final manuscript.

\section{Competing interests}

The authors declare that they have no competing interests.

Received: 28 April 2011 Accepted: 28 June 2011 Published: 28 June 2011

\section{References}

1. Ho JH: An epidemiologic and clinical study of nasopharyngeal carcinoma. Int J Radiat Oncol Biol Phys 1978, 4:182-198.

2. Lee AW, Poon YF, Foo W, Law SC, Cheung FK, Chan DK, Tung SY, Thaw M, Ho JH: etrospective analysis of 5037 patients with nasopharyngeal carcinoma treated during 1976-1985: overall survival and patterns of failure. Int J Radiat Oncol Biol Phys 1992, 23:261-270. 
3. Leong JL, Loh KS, Putti TC, Goh BC, Tan LK: Epidermal growth factor receptor in undifferentiated carcinoma of the nasopharynx. Laryngoscope 2004, 114:153-157.

4. Zheng X, Hu L, Chen F, Christensson B: Expression of Ki67 antigen, epidermal growth factor receptor and Epstein-Barr virus-encoded latent membrane protein (LMP1) in nasopharyngeal carcinoma. Eur J Cancer 1994, 30B: 290-295.

5. Roychowdhury DF, Tseng A Jr, Fu KK, Weinburg V, Weidner N: New prognostic factors in nasopharyngeal carcinoma. Tumor angiogenesis and C-erbB2 expression. Cancer 1996, 77:1419-1426.

6. Ma BB, Lui WW, Poon FF, Wong SC, To KF, Wong E, Chen H, Lo KW, Tao Q, Chan AT, Ng MH, Cheng SH: Preclinical activity of gefitinib in nonkeratinizing nasopharyngeal carcinoma cell lines and biomarkers of response. Invest New Drugs 2010, 28:326-333.

7. Ma BB, Poon TC, To KF, Zee B, Mo FK, Chan CM, Ho S, Teo PM, Johnson PJ, Chan AT: Prognostic significance of tumor angiogenesis, Ki 67, p53 oncoprotein, epidermal growth factor receptor and HER2 receptor protein expression in undifferentiated nasopharyngeal carcinoma - a prospective study. Head Neck 2003, 25:864-872.

8. Pan J, Kong L, Lin S, Chen G, Chen Q, Lu JJ: The clinical significance of coexpression of cyclooxygenases-2, vascular endothelial growth factors, and epidermal growth factor receptor in nasopharyngeal carcinoma. Laryngoscope 2008, 118:1970-1975.

9. Sung FL, Poon TC, Hui EP, Ma BB, Liong E, To KF, Huang DP, Chan AT Antitumor effect and enhancement of cytotoxic drug activity by cetuximab in nasopharyngeal carcinoma cells. Vivo 2005, 19:237-245.

10. Xiao X, Wu J, Zhu X, Zhao P, Zhou J, Liu QQ, Zheng L, Zeng M, Liu R, Huang W: Induction of cell cycle arrest and apoptosis in human nasopharyngeal carcinoma cells by ZD6474, an inhibitor of VEGFR tyrosine kinase with additional activity against EGFR tyrosine kinase. Int J Cancer 2007, 121:2095-2104.

11. Olayioye MA, Neve RM, Lane HA, Hynes NE: The ErbB signaling network: receptor heterodimerization in development and cancer. EMBO J 2000, 19:3159-3167.

12. Blagoev B, Ong SE, Kratchmarova I, Mann M: Temporal analysis of phosphotyrosine-dependent signaling networks by quantitative proteomics. Nat Biotechnol 2004, 22:139-1345.

13. Van den Bergh G, Arckens L: Fluorescent two-dimensional difference gel electrophoresis unveils the potential of gel-based proteomics. Curr Opin Biotechnol 2004, 15:38-43.

14. Friedman DB, Hill S, Keller JW, Merchant NB, Levy SE, Coffey RJ, Caprioli RM: Proteome analysis of human colon cancer by two-dimensional difference gel electrophoresis and mass spectrometry. Proteomics 2004 4:793-811.

15. Wessel D, Flugge UI: A method for the quantitative recovery of protein in dilute solution in the presence of detergents and lipids. Anal Biochem 1984, 138: 141-143

16. Chen Y, Ouyang GL, Yi H, Li MY, Zhang PF, Li C, Li JL, Chen ZC, Xiao ZQ: Identification of RKIP as an invasion suppressor protein in nasopharyngeal carcinoma by proteomic analysis. J Proteome Res 2008, 7:5254-5262

17. Diella F, Gould CM, Chica C, Via A, Gibson TJ: Phospho.ELM: a database of phosphorylation sites-update 2008. Nucleic Acids Res 2008, 36:D240-244.

18. Dennis G Jr, Sherman BT, Hosack DA, Yang J, Gao W, Lane HC, Lempicki RA: DAVID: Database for Annotation, Visualization, and Integrated Discovery. Genome Biol 2003, 4:P3.

19. Huang DW, Sherman BT, Lempicki RA: Systematic and integrative analysis of large gene lists using DAVID Bioinformatics Resources. Nature Proto 2009, 4:44-57

20. Yang Y, Xiao Z, Chen Z, Zhang G, Yi H, Zhang P, Li J, Zhu G: Proteome analysis of multidrug resistance in vincristine-resistant human gastric cancer cell line SGC7901/VCR. Proteomics 2006, 6:2009-2021.

21. Nikitin A, Egorov S, Daraselia N, Mazo I: Pathway studio-the analysis and navigation of molecular networks. Bioinformatics 2003, 19:2155-2157.

22. Prenzel N, Fischer OM, Streit S, Hart S, Ullrich A: The epidermal growth factor receptor family as a central element for cellular signal transduction and diversification. Endocr Relat Cancer 2001, 8:11-31.

23. Hayes JD, Pulford DJ: The glutathione S-transferase supergene family: regulation of GST and the contribution of the isoenzymes to cancer chemoprotection and drug resistance. Crit Rev Biochem Mol Biol 1995, 30:445-600.
24. Mulder TP, Verspaget HW, Sier CF, Roelofs HM, Ganesh S, Griffioen G, Peters WH: Glutathione S-transferase pi in colorectal tumors is predictive for overall survival. Cancer Res 1995, 55:2696-2702.

25. Peters WH, Wormskamp NG, Thies E: Expression of glutathione Stransferases in normal gastric mucosa and in gastric tumors. Carcinogenesis 1990, 11:1593-1596.

26. Ishioka C, Kanamaru R, Shibata H, Konishi Y, Ishikawa A, Wakui A, Sato T, Nishihira T: Expression of glutathione S-transferase-pi messenger RNA in human esophageal cancers. Cancer 1991, 67:2560-2564.

27. Wang X, Pavelic ZP, Li Y, Gleich L, Gartside PS, Pavelic L, Gluckman JL, Stambrook PJ: Overexpression and amplification of glutathione Stransferase pi gene in head and neck squamous cell carcinomas. Clin Cancer Res 1997, 3:111-114

28. Goto S, lida T, Cho S, Oka M, Kohno S, Kondo T: Overexpression of glutathione S-transferase pi enhances the adduct formation of cisplatin with glutathione in human cancer cells. Free Radic Res 1999, 31:549-558.

29. Chen $C L$, Sheen $T S$, Lou IU, Huang AC: Expression of multidrug resistance 1 and glutathione-S-transferase-Pi protein in nasopharyngeal carcinoma. Hum Pathol 2001, 32:1240-1244

30. Jayasurya A, Yap WM, Tan NG, Tan BK, Bay BH: Glutathione S-transferase pi expression in nasopharyngeal cancer. Arch Otolaryngol Head Neck Surg 2002, 128:1396-1399.

31. Okamura T, Singh S, Buolamwini J, Haystead T, Friedman H, Bigner D, AliOsman F: Tyrosine phosphorylation of the human glutathione $\mathrm{S}$ transferase P1 by epidermal growth factor receptor. J Biol Chem 2009, 284:16979-16989.

32. Hsu CH, Gao M, Chen CL, Yeh PY, Cheng AL: Inhibitors of epidermoid growth factor receptor suppress cell growth and enhance chemosensitivity of nasopharyngeal cancer cells in vitro. Oncology 2005, 68:538-547.

doi:10.1186/1477-5956-9-35

Cite this article as: Ruan et al:: Analysis of EGFR signaling pathway in nasopharyngeal carcinoma cells by quantitative phosphoproteomics. Proteome Science 2011 9:35.

\section{Submit your next manuscript to BioMed Central and take full advantage of:}

- Convenient online submission

- Thorough peer review

- No space constraints or color figure charges

- Immediate publication on acceptance

- Inclusion in PubMed, CAS, Scopus and Google Scholar

- Research which is freely available for redistribution

Submit your manuscript at www.biomedcentral.com/submit
C Biomed Central 